\title{
Airtight, flexible, disposable barrier for extubation
}

\author{
Kayo Hirose ${ }^{1}\left[\right.$ [ $\cdot$ Kanji Uchida ${ }^{1} \cdot$ Shinjiro Umezu ${ }^{2}$
}

Received: 20 May 2020 / Accepted: 31 May 2020 / Published online: 14 June 2020

(c) Japanese Society of Anesthesiologists 2020

To the Editor:

A barrier should be developed to protect medical staffs from droplets and aerosols containing SARS-CoV-2. The aerosol box [1] is one such barrier, but further improvement is required. We devised a Balloon for Aerosol Protection (BAP) that drastically decreases the risk of infection. It is an airtight protective device even when patient moves head, with built-in glove covers that a laryngoscopist can move his hands at will (ESM Figure 1).

First, we trialed the BAP with the laryngoscopist extubating the mannequin inside the sealed BAP. Before awakening from anesthesia, insert the underside of the BAP under the head and put the top side of the BAP on the mannequin. Pass the Heat and Moisture Exchanger and suction tube through the holes of the BAP and tape up the gaps. Put the necessary items, such as suction catheters, cuff syringe, surgical mask and anaesthetic mask, inside the BAP in advance. Seal BAP to the patient to almost airtight condition. The transparency and flexibility of the polyethylene bag facilitated successful suction and extubation. The patient's respiration is maintained using an anaesthetic mask, while aerosols generated inside the BAP are removed by ordinary suction equipment inserted through the BAP (ESM Movie 1).

Second, we spread a fluorescent as pseudo droplets and aerosols inside the BAP, and confirmed isolation of the operator's hands from the BAP chamber (ESM Movie 2).

Caveats: The completely sealed airtight condition inside the BAP might cause $\mathrm{CO}_{2}$ retention or a low $\mathrm{O}_{2}$ environment. Operators should be ready to tear off the BAP if the patients' condition requires re-intubation or other respiratory support.
Electronic supplementary material The online version of this article (https://doi.org/10.1007/s00540-020-02804-9) contains supplementary material, which is available to authorized users.

Kayo Hirose

hirosek-ane@h.u-tokyo.ac.jp

1 Department of Anesthesiology and Pain Relief Center, The University of Tokyo Hospital, 7-3-1 Hongo, Bunkyo-ku, Tokyo 113-8655, Japan

2 Modern Mechanical Engineering, Waseda University, Tokyo, Japan 
Acknowledgements The authors thank Xiaotong Li for technical support.

\section{Compliance with ethical standards}

Conflict of interest This study is supported by Konica Minolta Science and Technology Foundation.

\section{Reference}

1. Canelli R, Connor CW, Gonzalez M, Nozari A, Ortega R. Barrier enclosure during endotracheal intubation. N Engl J Med. 2020. https://doi.org/10.1056/NEJMc2007589.
Publisher's Note Springer Nature remains neutral with regard to jurisdictional claims in published maps and institutional affiliations. 